\title{
Moral Dilemmas in Serious Games
}

\author{
Jacqueline Krebs ${ }^{1}$ \\ ${ }^{1}$ Fraunhofer IDMT, Children's Media Department, Erfurt, Germany
}

\begin{abstract}
Why don't we decide or act in certain situations like we deem it right?

Decision-making and acting appropriately frequently differs in individual plans, resolutions, principles and attitudes from morality. This mismatch, between verdict and behavior, covers not only all areas of life but counts for daily acting as well. New requirements have to be shaped for a "moral" individual to be able to cope with especially difficult situations and to find a moral orientation in modern society. These demands should be age appropriate and able to be incorporated in education. Therefore the question is revealed; whether possibilities for an instruction of a moral conflict exist, offering the ability for a confrontation with subjective ethical values. This question forms the framework of the project "Catch 22", a serious game, developed for supporting juveniles in their ability to moral argumentation. The serious game is based on the perceptions of moral and pedagogic research and designed using taxonomic concepts of storyboarding. The target is to address the conflict of valid principles of morality and its influence on individual decision making and reasoning via gameplay. The support of moral argumentation through examination of "dilemmas in game" is in focus. Dealing with questions like: Can reflecting on a moral dilemma situation change one's mind? Are people amenable to moral reasoning while gaming?
\end{abstract}

Keywords: Argument Mapping, Critical Thinking, Game-Based Learning, Moral Dilemmas, Serious Games.

\section{Serious Games for Learning}

Games are a remarkable part of all known human cultures. Humans play games to learn new skills, to feel a sense of achievement, to interact with friends and family, and sometimes just to pass time. Digital games, in all its various formats and genres are just a new expression of this old method of social interaction. Digital games have the capacity to take the player to amazing new worlds with fantastic characters and fully realized interactive environments [5]. A subset of digital games is the serious games genre.

Before discussing the issue, what exactly is hidden behind the terminology of serious games and how it is related to learning through playing, it makes sense to briefly deal with games themselves.

Games include many forms of learning. It thus serves to the acquisition of skills, knowledge and experience, while also for experimentation and rediscovery. A game referring to [14] is a system in which players engage in an artificial conflict, defined by rules, which result in a quantifiable outcome. If we take the view of [12] "All games are serious", you must direct your focus on the target group, for what purpose and under which conditions a game is developed [6]. Contemporary classifications such as [13] describe Serious Games as any form of interactive computer-based game-software that has been developed with the intention to be more than entertainment. [6] referred to this definition, as "less practical" and criticized the fact that no one can know the intentions of the developers in game. Additionally, there is not even a need to 
start/or play the game to say something about the intentions of the developers' experience. Instead, the author of [6] suggests a modification of the concept formation and describes serious games as games, which are capable of more than entertainment. This definition implies that each digital game is a serious game. This means that with every game you can learn something, be it for example the interface design or software technology.

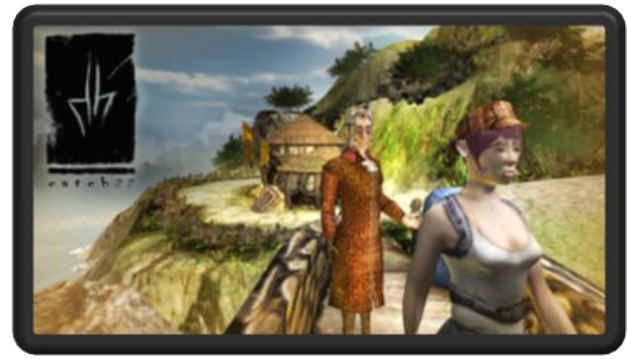

Fig. 1: The mystic Island of the Serious Game 'Catch 22'

The context of play must be considered if games are to be more than just entertainment. Taxonomic concepts of storyboarding can afford that, like [7] and [8].

The author of [3] describes the secret of a good game in its architecture, where each level dances around the outer limits of the player's abilities, seeking at every point to be hard enough to be just doable. Good design has the potential to support meaningful learning through a variety of content margins (see, for instance, [9]).

Effective learning, understood as knowledge construction, can't be enforced any more than the fun of playing: But you can create both excellent and stimulating playing conditions. Ask yourself, why do you play games?

\section{Moral Psychology in the Context of Computer Games}

Usually, you play to relax. The player, e.g. as a hero, is fighting for the righteous cause, wins and feels good. But there are also games that choose a different approach, arousing less pleasant feelings. Games, or at least certain situations in games, that give the player a thick lump to swallow, raise doubts or leave them feeling guilty. A type of game conflict can come from dilemma-based choices that players have to make. A dilemma can be a powerful source of conflict.

Moral dilemmas are situations where players must weigh the consequences of their choices carefully, because there are at least two or more values battling for the 'pole position' and there is no optimal answer. Moral dilemmas are right up there when it comes to feeling bad or affected. Why?

It is because they demand a great deal of the player: things that are immoral, cruel or sad. Moral dilemmas, intentionally or not, provoke the violation of the learned value system or have no happy ending.

The psycho-thriller-adventure 'Heavy Rain', released for the PS 3 in 2010, is operating with moral dilemmas and pushes more than a precarious situation to mind: How far would you go for someone you love? Will you kill someone in order to save the life of another, even if the potential victim is a loving family man? Every little decision in the game can change everything. No question, most players like to choose the heroic path.

Unlike 'Heavy Rain', in which the player still has the choice to act immorally or righteous, other games are more rigid and face the player with accomplished facts. In the German third-person shooter 'Spec Ops: The Line' you must fire several phosphorus-shells into an enemy squad, in which there are also innocent civilians. 
The reason why moral psychology in the context of computer games is such a fascinating subject is not that we are confronted mercilessly with considerations between good and evil, but our understanding of different moral values, that the way we think and respond to important issues and questions in the real world, can change.

Thinking about this topic from a pedagogical perspective, you easily come to the point where it might make sense to use exactly these emotionally touching settings and combine it with the classical dilemma discussion Kohlberg [10] once invented. It is a structured method to discuss the pros and cons of a dilemma situation. Going further - focusing on Haidt's Social-Intuitionist Model and Moral Foundation Theory [4], where moral judgment is understood as a dual process of intuitive-affective reactions ("gut feeling") and cognitive-reflective processes (moral reasoning) in a social context.

Combining the altercation with dilemmas and gameplay, we have an effective tool focusing on critical thinking, change of perspectives and self-reflection. The idea merges in a serious game we called 'Catch 22' (see Fig. 1), using argument maps to illustrate the individual position and makes the moral reasoning obvious.

\section{The Significance of Moral Reason- ing and Critical Thinking}

Not uncommon in everyday life, different values compete with each other. Moral reasoning is an important factor for the sustainability of teaching values.

Moral reasoning is understood by the author as a key component in critical thinking. The term critical thinking defines a wide range of cognitive skills and intellectual dispositions needed to effectively identify, analyze, and evaluate arguments and truth claims (see [2] for further details); mainly to discover and overcome personal prejudices and biases; to formulate and present convincing reasons in support of conclusions; and to make reasonable, intelligent decisions about what to believe and what to do.

Furthermore, critical thinking is understood as a kind of evaluative thinking, which involves both criticism and creative thinking; and which is particularly concerned with the quality of reasoning or argument which is presented in support of a belief or a course of action [1].

Dealing with particular problems and situations to find a moral orientation, new requirements are formulated on a "moral" individual.

Whoever thinks and does this critical, is not just asking questions but also trying to answer them. You think of reasons why a question is meaningful or meaningless, if answers are true or false, acceptable or unacceptable. Critical thinking means, therefore, to accept arguments and conclusions, not blindly, but assumptions are subject to inspection. Argument mapping is a common tool to encourage critical thinking.

\section{Argument Mapping (in the Game)}

In general, argument mapping is described (see, [11]) as simply producing a diagram which shows the structure of an argument or set of arguments. Normally these are box-and-arrow diagrams, which can be found in this document (see Fig. 2 \& 3).

Argument mapping is akin to other mapping procedures such as mind mapping and concept mapping, but it focuses on the logical, evidential or inferential relationships among propositions. 


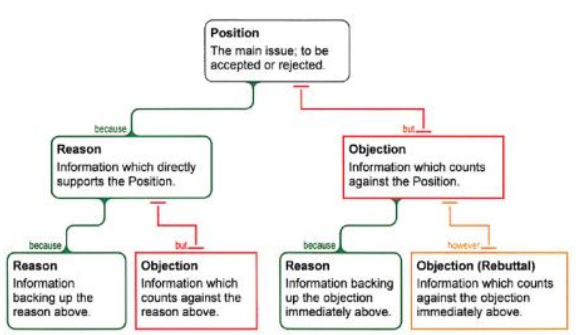

Fig. 2: Basic Structure of an Argument-Map

The figures $2 \& 3$ were created using the software Rationale developed by Austhink Software and should give you an impression of what the structure looks like. So, an argument-map is a twodimensional representation of argument structure, a diagram which resembles a tree.

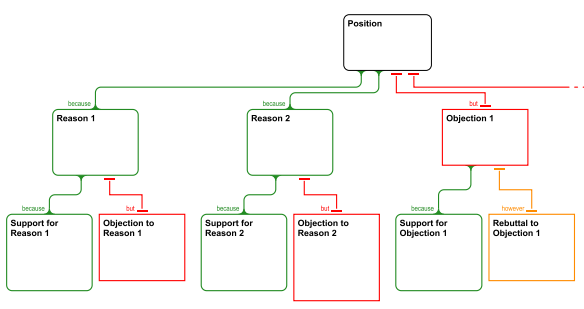

Fig. 3: A Multi-Branched Argument-Map

Using argument mapping in a game, the first step is to identify the players' main position in a dilemma situation. The game visualizes this, in a single, simple and general sentence and pictures the available reasons and objections the player has gathered.

The single elements can of course be combined in various ways as necessary to capture the structure of the dilemma while playing. Using argument mapping implemented in a game allows a greater level of clarity and insight, rigorous and complete articulation, more judicious evaluation and an better overview of a dilemma and the given pros and cons. It can be an effective way to improve general critical thinking skills.

\section{Implications for Further Education}

Arguments can be complicated, sometimes extremely so. Visualization can help our minds cope with the complexity of dilemmas in everyday life. In relation to further education and training, the implementation of argument mapping in games can also be adapted to the sector of executive development. Argument maps in games can promote rational resolution in complex, fractious decisions. Not just young adults need a broad understanding of important arguments and moral reasoning. Managers should also be able to think critically and constantly improve their communication and decisionmaking. They need appropriate technical, methodological and social skills. Dealing with virtually presented dilemmas will help in difficult situations to be able to make an informed decision and thereby to use analytical and combinatorial skills.

This work should serve as the basis for further research in supporting moral argumentation in games, a broad field requesting future investigations.

\section{Acknowledgement}

The research reported in this paper was supported by Klaus P. Jantke from Fraunhofer IDMT, head of the Children's Media Department, Erfurt, Germany.

Furthermore, I thank Christian Kirchner and Antonio Purrmann for the exceptional teamwork and artistic realization of 'Catch 22'.

\section{References}

[1] A. Fisher, "Critical Thinking. An Introduction", Cambridge a.o.: Cambridge University Press, 2006. 
[2] G. Bassham, W. Irwin, H. Nardone, J. Wallace, "Critical Thinking. A Student's Introduction", Third Edition, New York: McGraw-Hill, 2008.

[3] J. P. Gee, "What video games have to teach us about learning and literacy", New York: Palgrave Macmillan, 2003.

[4] J. Graham, B. A. Nosek, J. Haidt, R. Iyer, S. Koleva, P. H. Ditto, ,Mapping the moral domain", Journal of Personality and Social Psychology, 101, 366-385, 2011.

[5] T. Fullerton, C. Swain, S. S. Hoffman, "Game Design Workshop A Playcentric Approach", Elsevier Morgan Kaufmann, 2008.

[6] K. P. Jantke, „Potenziale und Grenzen des spielerischen Lernens", Digitale Lernwelt - „Serious Games “. Einsatz in der beruflichen Weiterbildung, M. Metz, F. Theis (Hrsg.): Bielefeld: Bertelsmann Verlag, 2011.

[7] K. P. Jantke and R. Knauf, "Didactic design through storyboarding: Standard concepts for standard tools", Proc. $4^{\text {th }}$ International Symposium on Information and Communication Technologies, Cape Town, South Africa, 2005, B.R. Baltes, L. Edwards, F. Galindo et al. (eds.), pp. 20-25, Dublin, Ireland: Computer Science Press, 2005.
[8] K. P. Jantke and R. Knauf, "Taxonomic concepts for storyboarding digital games for learning in context", 4th International Conference on Computer-Supported Education, CSEDU 2012, Porto, Portugal, M. Helfert, M.J. Martins, and J. Cordeiro (eds.), pp. 401-409, SciTePress, 2012.

[9] V. J. Shute, L. P. Rieber, R. van Eck, "Games and Learning", Trends and Issues in Instructional Design and Technology, R. A. Reiser, J. V. Dempsey, Third Edition, Pearson, 2012.

[10] L. Kohlberg, „Die Psychologie der Moralentwicklung“, Frankfurt am Main: Suhrkamp Verlag, 1995.

[11] T. van Gelder, "Argument mapping", Encyclopedia of the Mind, H. Pashler (ed.), Thousand Oaks, CA: Sage, 2013.

[12] B. Sawyer and P. Smith, Serious games taxonomy, http://www.serious games.org/presentations/seriousgames-taxonomy-2008_web.pdf, 2008 [last access: Dec. 12, 2009].

[13] U. Ritterfeld, M. Cody, P. Vorderer, "Serious Games. Mechanisms and Effects", New York, NY, USA: Routledge, 2009.

[14] K. Salen and E. Zimmerman, "Rules of Play: Game Design Fundamentals", The MIT Press, 2004. 